\title{
Jomtien to Jomtien: The Evolving Coordination Process of Education for All 1990-2011
}

\author{
Hiroshi Ito ${ }^{1}$ \\ ${ }^{1}$ United Nations Educational, Scientific, and Cultural Organization, France \\ Correspondence: Hiroshi Ito, United Nations Educational, Scientific, and Cultural Organization, France. E-mail: \\ h.ito@unesco.org
}

Received: May 24, 2012 Accepted: June 11, 2012 Online Published: July 31, 2012

doi:10.5539/ies.v5n5p1 URL: http://dx.doi.org/10.5539/ies.v5n5p1

\begin{abstract}
UNESCO's EFA coordination mechanisms have been serving political platforms for EFA stakeholders for over 20 years. During the Ninth Meeting of the High-Level Group on EFA (HLG) in 2010, however, UNESCO was called on to enhance the effectiveness of the coordination mechanisms. This paper examines the EFA coordination mechanisms between the World Conference in Jomtien in 1990 and the $10^{\text {th }}$ HLG in Jomtien in 2011 and identifies three reasons behind the call to revitalize the mechanisms: (1) EFA stakeholders' weakened commitment to EFA, (2) decreased education funding and (3) the diminished prospect of meeting EFA goals. The paper concludes by summarizing the direction of the new EFA coordination mechanisms that have been put in place since the HLG in 2011.
\end{abstract}

Keywords: education for all, coordination mechanisms, UNESCO, post-2015 agenda

\section{Introduction}

It has been over 20 years since the Education for All (EFA) movement was launched in Jomtien, Thailand in 1990. EFA is a global commitment to provide quality basic education (Note 1) for all children, youth and adults. In order for EFA stakeholders (e.g. governments, bilateral and international agencies, (Note 2) universities, civil society, non-governmental organisations and the private sector) to work together towards the attainment of EFA, UNESCO's EFA coordination mechanisms have been serving as platforms for promoting advocacy, reviewing progress, facilitating professional discussion and sharing knowledge and information. (Note 3) During the Ninth Meeting of the High-Level Group on EFA $\left(9^{\text {th }}\right.$ HLG) in 2010, however, UNESCO was called upon to enhance the effectiveness of the EFA coordination architecture. Since then, the organisation has been making efforts to redesign its coordination structure in order to improve the visibility of EFA, to mobilise resources and to accelerate progress on EFA (UNESCO, 2011a). (Note 4) The Tenth Meeting of the High-Level Group on EFA $\left(10^{\text {th }}\right.$ HLG) in 2011 was an experimental and transitional step towards a new EFA architecture. Yet, why has the revitalisation of the EFA coordination become an issue only recently despite the fact that the current EFA coordination mechanisms - mainly based on the Working Group (WG) and the High-Level Group (HLG) meetings - have basically remained unchanged in both function and format for the last ten years or so? Furthermore, the newly proposed structure is not very different from the existing one. Within the new structure, the WG and the HLG meetings are combined into a Global EFA Meeting (GEM) for progress review and policy dialogue. A High-Level Forum (HLF) is created as a political strategic body for advocacy. Yet, doesn't this structure mirror the original concept of the existing EFA coordination mechanisms, with the WG serving a technical role and the HLG a political one? With these questions in mind, this paper seeks to identify reasons behind the strong call to revitalise the EFA coordination mechanisms and to attempt to inform the direction of the new EFA coordination mechanisms by examining the evolving process of the EFA coordination mechanisms between the World Conference on Education in Jomtien in 1990 and the $10^{\text {th }}$ HLG in Jomtien in 2011, including the ongoing reform of the EFA coordination mechanisms. It should be noted that this paper focuses on the function of the EFA coordination mechanisms. An in-depth examination of the EFA agenda, including the post-2015 EFA, remains outside of the scope of this study. 


\section{EFA Coordination Mechanisms}

Many definitions have been provided for the term coordination. Malone and Crownstone, who developed coordination theory, defined coordination as a mechanism for allocating resources, structuring informational flows, organizing activity when multiple, connected actors pursue common goals (Malone, 1988), and managing dependencies, such as shared resources and task assignments, between activities (Malone and Crownstone, 1994). From these definitions, EFA coordination mechanisms can be seen as the organizing bodies representing the collective efforts of EFA partnerships toward the attainment of EFA.

Although the EFA coordination mechanisms were established after the 1990 Jomtien World Conference, it is not that the global partnerships for education among EFA stakeholders had not existed before the event. (Note 5) When the World Bank's education sector was hatching in the 1960s, for example, UNESCO sent its education experts to the World Bank to strengthen its support base (Saito, 2001). UNESCO also created the collective consultation of NGOs (CCNGO) in 1984 to facilitate collective commitment and action with civil society organizations.

The 1990 Jomtien Conference itself was a result of global partnerships for education. The conference was organized by the Inter-Agency Commissions established by UNDP, UNESCO, UNICEF, and the World Bank with 150 governments and other development organizations. Collective efforts made by EFA stakeholders through partnerships for education before, during and after the Jomtien Conference led to the establishment of the International Consultative Forum on EFA in 1991, as described in the following section. EFA coordination mechanisms provide platforms to facilitate and promote:

- The exchange of expertise and experiences

- Mobilisation and management of resources (for their efficient and effective use)

- The mapping of policy directives and initiatives for a clean division of labor

- The increase of visibility of and commitment to EFA through policy dialogue and advocacy work

- The monitoring of EFA progress

While the EFA coordination mechanisms dedicate to promote policy dialogue, monitoring, advocacy, mobilization of funding and capacity development, there are also several limitations for the EFA coordination mechanisms.

- Difficulty in measuring the impact of EFA coordination mechanisms on achievement: Although education indicators, such as net enrolment or gender parity, can be considered criteria for success or failure, causal relationships between coordination efforts and education performance remain unproved. Qualitative variables such as trust or good will, while recognized as essential for a successful partnership, are also impossible to measure objectively (Draxler, 2008).

- Issues of political and financial incentives and competition among EFA stakeholders: In many ways, the EFA coordination mechanisms can serve as a cartel. The public sector, private sector and civil society set common EFA goals instead of prices, for their own political and financial benefits. EFA stakeholders compete against others to increase their visibility rather than improving their performance through partnerships.

- Existing conceptual gaps between the policy level and the operational level: International education policies are guided by mission statements born out of the EFA meetings. The ones within the Jomtien Declaration and the Dakar Framework for Action are prime examples. However, these mission statements tend to focus on "what to say" at the policy level rather than making a concrete proposal for "what to do" at the operational level. The EFA Goals 3, which focuses on providing learning opportunities for youth and adults, as well as Goal 6, which centers on improving the quality of every aspect of education (albeit without suggesting clear indicators to measure these aspects except what is called a youth literacy rate or survival rate to grade 5), exemplify this issue. Indeed, the gaps between the policy and the operational level have generated criticisms that the EFA coordination mechanisms have been unresponsive to national needs (UNESCO, 2011a).

\section{Overview of EFA 1990-2011}

There have been two recognised EFA coordination mechanisms since the movement's inception. The first was the International Consultative Forum on EFA from 1991 to 2000. (Note 6) This Forum was created to maintain the momentum of EFA through meetings and follow-up activities after the Jomtien Conference in 1990. The second EFA coordination mechanisms spanned from the year 2000 to the present. The mechanisms assume the 
format of the WG-HLG and function to increase the visibility of EFA in the international agenda, to mobilise technical and financial resources and to monitor EFA progress. Increasing the visibility of EFA enhances stronger commitments to EFA, which in turn helps facilitate resource mobilisation. Increased resources are expected to help improve educational outcomes. While their causal relationships remain unproved, EFA stakeholders assume that visibility, resource and education indicators are correlated and expect the EFA coordination mechanisms to increase visibility, mobilise resources and monitor progress.

\subsection{EFA 1990-2000}

Although provision of universal basic education had long been discussed, it was at the World Conference on EFA in Jomtien in March 1990 that EFA became globally recognised. At the time of the conference, there existed more than 100 million children, including at least 60 million girls, who had no access to primary schooling. There were also more than 960 million illiterate adults, two-thirds of whom were women, and functional illiteracy was a significant problem in both developed and developing countries. In order to address these and other educational issues, the following six dimensions were suggested in the World Declaration on EFA adopted at the Jomtien Conference:

1) expansion of early childhood care and development activities, including family and community interventions, especially for poor, disadvantaged and disabled children; 2) universal access to, and completion of, primary education (or whatever higher level of education is considered 'basic') by the year $2000 ; 3$ ) improvement of learning achievement such that an agreed percentage of an age cohort (e.g. $80 \%$ per cent of 14-year-olds) attains or surpasses a defined level of necessary learning achievement; 4) reduction of the adult illiteracy rate (the appropriate age-group to be determined in each country) to, for example, one half its 1990 level by the year 2000, with sufficient emphasis on female literacy to significantly reduce the current disparity between male and female illiteracy rates; expansion of the provision of basic education and training in other essential skills required by youth and adults, with programme effectiveness assessed in terms of behavioural change and impact on health, employment and productivity; 6) increased acquisition by individuals and families of the knowledge, skills and values required for better living and sound and sustainable development, made available through all education channels including the mass media, other forms of modern and traditional communication, and social action, with effectiveness assessed in terms of behavioural change (UNESCO, 1990, p. 90).

In spite of its comprehensive approach, the focus of the World Declaration on EFA was mainly limited to achieving universal primary education, and to a lesser extent, improving gender parity and reducing adult illiteracy. (Note 7) While UNESCO intended to introduce an inclusive concept of basic education that included early childhood education, adult education and others rather than primary education alone, UNICEF and the World Bank, two of the convening agencies, announced at the conference that they would prioritise primary education because "primary schooling, for UNICEF and the World Bank, was politically and numerically a much more attractive target than the worlds of early childhood, adult literacy, and adult and youth skills (King, 2007, p. 380). Understanding the key roles of the World Bank and UNICEF in shaping the direction and implementation of EFA is crucial to analysing why EFA has been associated with universal primary education.

In order to maintain the momentum of EFA (by developing and following up the outcome of Jomtien, assisting in the mobilisation of interest in and resources for EFA, and helping implement national action plans), an International Consultative Forum on EFA was established in 1991, which included a Forum Secretariat housed in the UNESCO Headquarters and a Forum Steering Committee comprising the representatives of the EFA convening agencies. (Note 8) Three major meetings organised by the International Consultative Forum on EFA took place in 1991 (Paris, France), 1993 (New Delhi, India) and 1996 (Amman, Jordan), and provided a global EFA coordination structure for reviewing EFA progress and discussing issues of common interest (Skilbeck, 2000). After the Amman Forum, the Secretariat and Steering Committee began to plan for the EFA 2000 Assessment. The EFA Forum's Global Technical Advisory Group, composed of specialists from the five EFA convening agencies (i.e. UNICEF, UNESCO, UNDP, WB and UNFPA), prepared the general and technical guideline for the assessment. (Note 9) The Regional Technical Advisory Group was also established to coordinate and support countries' exercises. The National Assessment Group comprising national planners, school inspectors, statisticians and researchers conducted data collection and analysis.

Despite a multitude of efforts made by governments, development organisations and others between the Jomtien conference and the end of the millennium, the EFA 2000 Assessment revealed discouraging results, especially in many developing countries (UNESCO, 2000). Although there was evidence of some improvement, such as in 
total international aid to education (e.g. an increase from $\$ 138$ billion in 1991 to $\$ 248$ billion in 1999, though the peak in the 1990s was $\$ 345$ billion in 1996) and in increase of educational access (UNESCO, 2001), drastic increases in population in many developing countries sometimes outpaced the increase in enrolment rates. (Note 10) Indeed, while the world's net enrolment at the primary level increased from $78.7 \%$ in 1990 to $82 \%$ in 1999 , according to the 2001 EFA Global Monitoring Report (UNESCO 2001), the number of out-of-school children did not decrease at all. Similarly, the world's literacy rate improved from $75.3 \%$ in 1990 to $79.7 \%$ in 2000 , but there were still more than 850 million adult illiterates, 550 million of whom were women.

Along with the quantity, the quality of education has long been a serious matter of interest. In the World Conference on EFA in 1990, the constituent agencies agreed to measure universal access to education "not on the basis of school attendance, but on the basis of what children learned" (Heyneman, 1999, p. 71). However, the quality of education deteriorated in many developing nations in the last decade of the 20th century in part because the increase in overall student enrolment required more schools, more teachers, and more educational materials, which were not adequately provided. Especially in rural areas where the majority of the poor live (World Bank, 2008), the schooling of children is too often neglected in part because there is a lack of financial as well as technical resources for education. As Langhammer (1999) points out, accessible public services, including education, tend to be concentrated in urban areas due to economies of scale and other factors, which leads to inequity regarding the quality of the education for rural students (Considine and Zappalà, 2002).

\subsection{EFA 2000-2010}

To reaffirm the EFA agenda, the international community gathered for a second world conference on education called the World Education Forum in Dakar, Senegal, in April 2000. The Forum adopted the Dakar Framework for Action and identified six EFA goals to be met by 2015:

1) expanding and improving comprehensive early childhood care and education, especially for the most vulnerable and disadvantaged children; 2) ensuring that by 2015 all children, particularly girls, children in difficult circumstances and those belonging to ethnic minorities, have access to and complete free and compulsory primary education of good quality; 3 ) ensuring that the learning needs of all young people and adults are met through appropriate learning and life skills programmes; 4) achieving a 50\% improvement in levels of adult literacy ( 15 years old and above) by 2015, especially for women, and equitable access to basic and continuing education for all adults; 5) eliminating gender disparities in primary and secondary education by 2005 and achieving gender equality in education by 2015, with a focus on ensuring girls' full and equal access to and achievement in basic education of good quality; 6) improving every aspect of the quality of education, and ensuring excellence so that recognised and measurable learning outcomes are achieved by all, especially in literacy, numeracy and essential life skills (UNESCO, 2000, p. 15-17).

As these EFA goals were set forth in Dakar, UNESCO attempted to reintroduce its inclusive basic education policy, while the World Bank and UNICEF remained focused on primary education, especially for girls. The Dakar Forum also called for the systematic monitoring and evaluation of EFA as well as the creation of a new EFA coordination structure and appointed UNESCO to manage both these tasks as the organisation had already led efforts in EFA coordination:

Systematically monitor progress towards EFA goals and strategies at the national, regional and international levels: Achieving EFA goals requires setting priorities, defining policies, establishing targets and progress indicators, allocating resources, monitoring performance, and assessing qualitative and quantitative outcomes. Robust and reliable education statistics, disaggregated and based on accurate census data, are essential if progress is to be properly measured, experience shared and lessons learned. Information on the success of particular strategies, on national and international budget allocations for basic education and on civil society participation in EFA must also be sought. These are all key elements in assessing the accountability of EFA partners. Ongoing monitoring and evaluation of EFA, with the full participation of civil society, should be encouraged (UNESCO, 2000, p. 21).

Build on existing mechanisms to accelerate progress towards EFA: In order to realise the six goals presented in this Framework for Action, broad-based and participatory mechanisms at international, regional and national levels are essential. The functions of these mechanisms will include, to varying degrees, advocacy, resource mobilisation, monitoring, and knowledge generation and sharing.....UNESCO will continue its mandated role in coordinating EFA partners and maintaining their collaborative momentum. In line with this, UNESCO will annually convene a high-level, small and flexible group to serve as a lever for political commitment and technical and financial resource 
mobilisation. It will be composed of leaders from governments and civil society and development agencies. UNESCO will refocus its education programme in order to place the outcomes and priorities of Dakar at the heart of its work (UNESCO, 2000, p. 21-22).

The Dakar Forum established the framework for the existing EFA coordination architecture with the annual WG and the HLG meetings based on progress reviews subsumed within the EFA Global Monitoring Report (GMR) (Note 11) instead of the irregular meetings organised by the International Consultative Forum on EFA in the 1990s. (Note 12) The WG provides an opportunity for information exchange and technical guidance among EFA partners while the purposes of the HLG are "to maintain high political commitment for EFA, to mobilise international financial support and to define strategies for progress towards EFA" (UNESCO, 2001, p. 11). Overall, the main functions of these EFA coordination mechanisms are to increase the visibility of EFA in the international political agenda, to mobilise technical and financial resources and to monitor and evaluate EFA progress. The first WG took place in November 2000 and the first HLG occurred in October 2001. (Note 13)

After the World Education Forum in 2000, EFA became linked to the Millennium Development Goals (MDGs), another set of global commitments to reduce extreme poverty by 2015. Out of the eight goals, (Note 14) MDGs 2 and 3 are closely related to EFA: the achievement of universal primary education by 2015 , whereby every child will complete a full course of primary education; and the promotion of gender equality and the empowerment of women with, specifically, the elimination of gender disparities at primary and secondary school levels by 2005 and across all education levels by 2015 (UNESCO 2010a, 4). Since then, emphasis has been almost exclusively placed on the achievement of universal primary education and the elimination of gender disparity under the EFA framework. As King (2007, p. 386) describes, "the achievement of free and compulsory primary education of good quality of the Dakar text was back to merely achieving universal primary education. [While] gender equality and the empowerment of women were retained...all the other 4 Dakar Targets were left aside." Heyneman (2009, p. 4) also asserts that the fact that major development agencies placed school enrolment and gender parity at the primary level as the top priority after the Dakar Forum "changed the rationale of education from being the infrastructure necessary for a democracy to being little more than a charitable handout for rural girls." While I argue that the focus on universal primary education, especially for disadvantaged girls in rural areas, was a necessary step for promoting EFA at that time, the EFA coordination mechanisms have struggled to switch from this idea that EFA is primarily about access to primary education and gender equality to the original concept of EFA as a good quality basic education for all.

\subsection{EFA 2010-11}

Since its launch in 2000-2001, the EFA coordination architecture based on the WG and HLG has basically remained the same in function and format. The improvement in EFA indicators and the increase of international aid for EFA peaked in the early 2000s, as will be discussed in a later section. Ten years after the WG-HLG EFA coordination mechanisms were put in place, however, the Addis Ababa Declaration, presented at the $9^{\text {th }}$ HLG (Addis Ababa, Ethiopia, 23-24 February 2010), raised the issue of revising them.

Increasing political and financial support for EFA will depend, to a large extent, on linking the campaign for EFA to broader development agendas. The urgency of meeting EFA calls for a revitalised EFA High-Level Group and better EFA coordination at all levels. We call on UNESCO, under its new leadership and informed by other external reviews, to propose concrete measures at the time of the MDG Summit [September 2010] to enhance the effectiveness of the High-Level Group and the underpinning coordination architecture, in order to boost political leadership and mutual accountability (UNESCO, 2010c, p. 3-4).

In response to the request, UNESCO began reforming the EFA coordination mechanisms and working on a draft paper, Enhancing Effectiveness of the EFA Coordination, through consultation with EFA partners, exploring the possible adoption of a new EFA coordination architecture.

At the $11^{\text {th }}$ WG (Paris, France, 2-3 February 2011), concern with the innovation of the EFA coordination mechanisms was expressed by UNESCO's Director-General, Assistant Director-General for the Education Sector and Director of EFA Global Partnerships Team. They underlined their commitment to the process of improving the effectiveness of EFA coordination, highlighting the need to strengthen coordination links among the national, regional and global levels (Note 15) in order to enhance the impact of the EFA meetings (e.g. the WG and the HLG) on the international community's awareness of the significance of EFA in international political events (e.g. the MDG Summit in New York in September 2010).

The issue of the EFA coordination was further addressed at the $10^{\text {th }}$ HLG (Jomtien, Thailand, 22-24 March 2011). The invitees to the HLG were limited to ministerial-level officials in order to make the meeting smaller 
and to allow for more substantive discussion and higher-level political impact than previous HLG meetings. The $11^{\text {th }}$ WG and the $10^{\text {th }}$ HLG were attempts at least in some respects to improve the existing EFA coordination structure. In the former meeting, UNESCO intended to strengthen coordination linkages at the national, regional and global levels by focusing on regional coordination and presenting regional reports as part of a progress review process carried out by the representatives of UNESCO's four Regional Bureaus of Education, including two directors. The latter meeting was smaller, with more high-level participants in order to be more politically influential and to increase the visibility of EFA and thus mobilise efforts and resources. Likewise, a new EFA coordination structure is expected to improve coordination linkages at the national, regional and global levels and to increase the political commitment of stakeholders to resource mobilisation.

\section{Why EFA Coordination is an Issue Now}

Why were the EFA coordination mechanisms suddenly raised as an issue during the $9^{\text {th }}$ HLG in Addis Ababa in 2010? As described above, the framework of the WG-HLG EFA coordination structure was created in 2000-2001 and had remained approximately the same in function and format until 2011. In the next few sections, I explore potential reasons(s) for the recent strong call to revitalise the EFA coordination mechanisms.

\subsection{Success in the Early 2000s}

In the early 2000s, education was a top priority on the international development agenda. Correspondingly, aid to education increased and improvement was observed in educational indicators. The World Education Forum in Dakar was successful in drawing the attention of EFA stakeholders, notably UNICEF and the World Bank, and in mobilising financial and technical resources. Furthermore, in relation to MDGs 2 and 3, the focus of EFA was clear: increasing access to primary education and improving gender parity. In addition, "strong economic growth and poverty reduction [between 2000 and the global financial crisis] helped boost advances in education" (UNESCO, 2011b, p. 113). Indeed, EFA indicators such as net enrolment rate (NER: the number of children of the school-age population enrolled at school as a percentage of the total number of school-age children) and gender parity index (GPI: the percentage of female students enrolled at school to that of male students) at the primary level improved substantially during this period: NER improved from $83.8 \%$ in 2000 to $87 \%$ in 2005 and GPI improved from 0.93 in 2000 to 0.96 in 2005 . According to UNESCO's (2007, p. 42) 2008 GMR, "global primary school enrolment rose from 647 million to 688 million (6.4\%) between 1999 and 2005, with increase especially marked in sub-Saharan Africa (by 29 million, 36\%), and South and West Asia (by 35 million, 22\%)." The same GMR also indicated that 118 countries of the 188 for which data were available had achieved gender parity at the primary level by 2005 .

\subsection{Downturn in the Late 2000 s}

Since the mid-2000s, however, the priority given to education on the international educational development agenda seems to have decreased. For example, Table 1 suggests that recently, fewer of UNESCO's Member States have mentioned EFA in the General Conference (GC). (Note 16)

Table 1. Number of Member States that mentioned EFA during the GCs

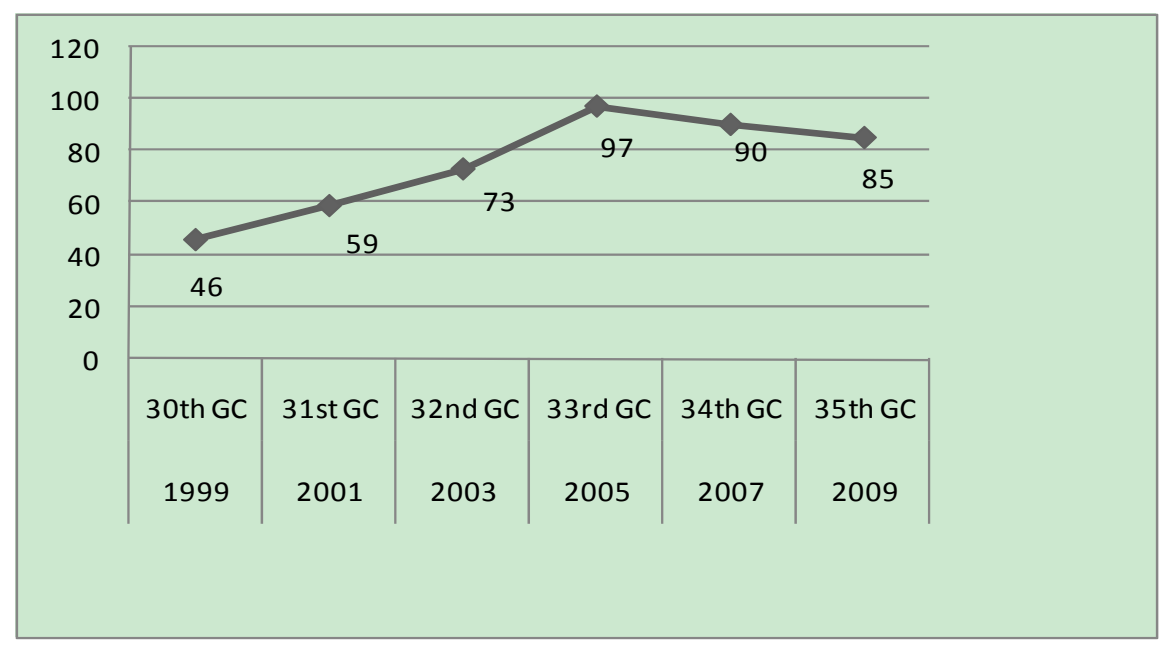

Source: UNESCO's General Conferences $30^{\text {th }}-35^{\text {th }}$ Resolutions 
After the number of countries that mentioned EFA more than doubled between 1999 and 2005, it decreased from 97 in 2005 to 85 in 2009. The EFA Global Monitoring Report sets a threshold of 3\% as a significant difference; according to this criterion, the difference of more than $5 \%$ in the number of countries mentioning EFA between 2005 and 2009 is thus considered significant.

With regard to the statements of Member States, it is noteworthy that already during the $33^{\text {rd }}$ General Conference held in 2005, a Member State requested that UNESCO change the HLG constitution for the attainment of EFA. As Norway's Minister of Education and Research stated, "as coordinator of the global process UNESCO needs to play a strong advocacy role as the world's never-resting conscience... [and] strengthen its global policy role. A first step could be to revitalise the High-Level Group and make it a strategic body for decision-making on policy directions. I would like to ask the Secretariat urgently to consider new ways and methods to meet this challenge efficiently" (UNESCO, 2005, p. 172). Global Campaign for Education (2009), a civil society movement for education, also expressed its frustration about the HLG's lack of "the dynamic leadership and decision-making power to really drive the international effort to achieve EFA" (1). These statements may imply that EFA coordination had long been in need of change, but was not considered an urgent issue by most Member States. There are some possible reasons for this: 1) the EFA coordination mechanisms were still in a developmental stage or incubation period during the early 2000s and few Member States had strong opinions of how they should be structured; 2) education had been a top priority on the international development agenda during that period and thus few criticisms of the coordination of EFA were brought up.

Along with the commitment of EFA stakeholders, the EFA progress, especially NER, has stagnated, as Table 2 shows.

Table 2. EFA Progress in NER

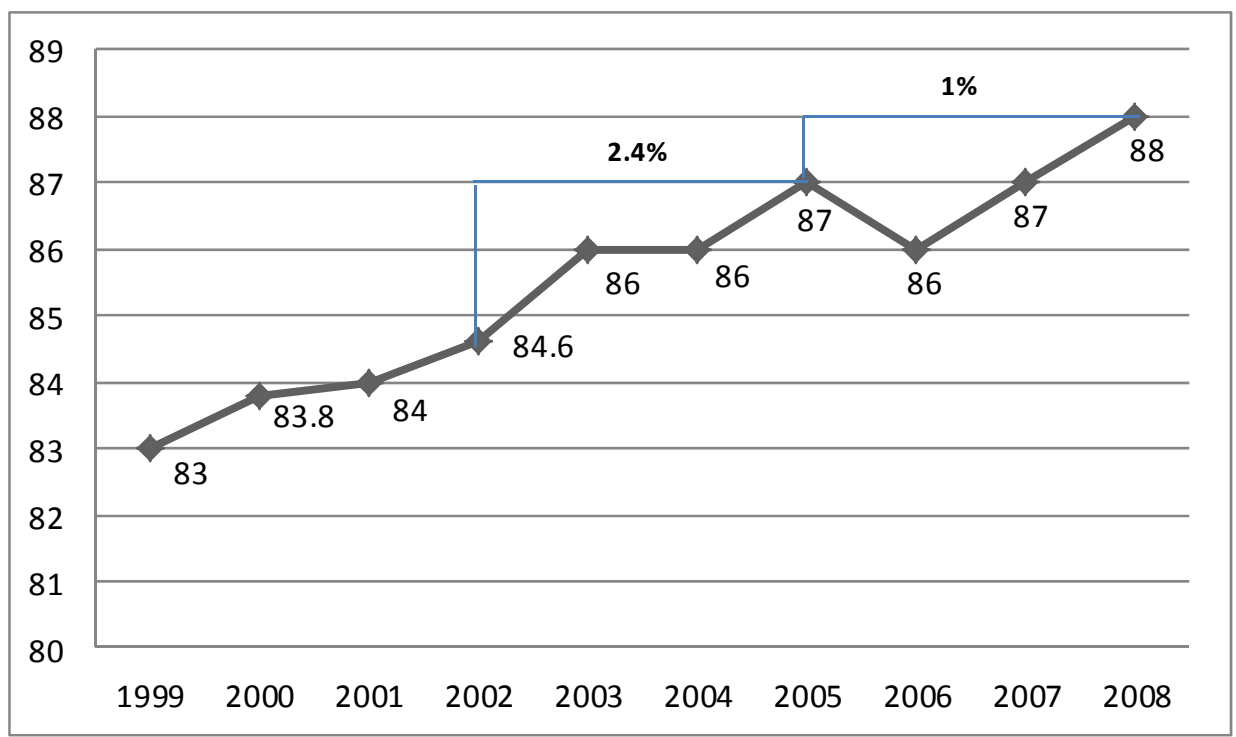

Source: EFA Global Monitoring Reports (GMRs) 2003/4 - 2011

Despite the fact that EFA indicators actually improved in the past ten years or so (e.g. NER improved from $82 \%$ in 1999 to $88 \%$ in 2008, while GPI improved from 0.94 in 1999 to 0.98 in 2008), UNESCO's 2011 (2011b) GMR reports that progress on EFA has recently slowed and NER improved by only one per cent between 2005 and 2008. (Note 17) In addition, UNESCO's 2011 (2011b, p. 24) GMR states that the future prospects for EFA are worsening:

Progress towards the key goals has been too slow and uneven... While out-of-school numbers are still declining, the rate of decline has slowed: during the second half of the past decade it fell more slowly than in the first half of the decade. If current trends continue there could be more children out of school in 2015 than there are today...Too many governments are moving too slowly to eliminate gender disparities 
The question remains, however, whether or to what extent these mishaps are to be imputed to the performance of the EFA coordination mechanisms. It is possible that the decreasing priority of education can be ascribed to the inefficiencies of EFA coordination mechanisms, which have failed to retain global education stakeholders. However, from a different vantage point, it is also possible to argue that the successes of increased net enrolment and improved gender parity in primary education during the early 2000s (arguably results of the EFA coordination efforts such as the Dakar World Education Forum and the WG-HLG EFA coordination mechanisms, which promoted EFA and mobilised resources) may have contributed to the later relative lack of attention given to education. Given that school enrolment and gender parity at the primary level improved remarkably during that period, as Heyneman (2009) warns, some now seem to believe that EFA has essentially been achieved and that further attention is thus unnecessary, despite the fact that EFA includes other goals beyond universal primary education and gender equality, (Note 18) such as early childhood education, adult literacy, education quality, vocational and adult education, which themselves are at risk of not being achieved.

The financial crisis that occurred in the late 2000s also aggravated the problem. As Table 3 indicates, aid to education decreased in 2008 for the first time since 2002.

Table 3. Aid Disbursement to Education 2002-2008 (Constant 2008 US\$ billion)

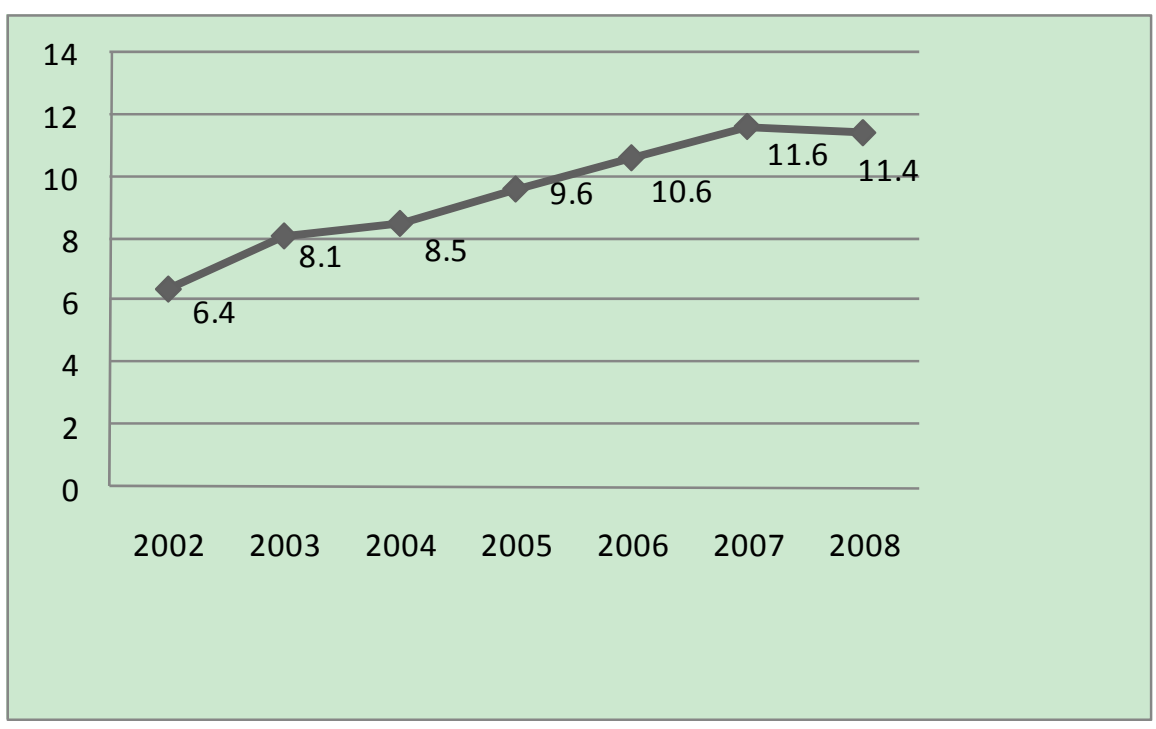

Source: GMR 2011

According to the 2011 EFA Global Monitoring Report (UNESCO, 2011b, p. 101):

The financial crisis has had an impact on government spending on education. Analysis undertaken in the policy focus section shows that seven of the eighteen low-income countries with available data cut education spending in 2009. In other countries the rate of increase in education spending has slowed considerably. Post-crisis plans to reduce fiscal deficits threaten to undermine financing plans for achieving the EFA goals

The decrease of aid to education, however, does not necessarily betoken lower commitment of EFA stakeholders, as the aftereffects of the financial crisis in the late 2000s could not be mitigated solely by their efforts. Also, according to UNESCO's (2011b) 2011 GMR, the decrease in aid to education can largely be ascribed to a change in reporting methods by France and to a decrease in aid from the International Development Association, which is influential but is not necessarily representative of EFA stakeholders. Thus, one reason that EFA is now in danger of not being achieved by 2015 may be partially financial as UNESCO's (2011b, p. 25) 2011 GMR warns:

After the Dakar World Education Forum in 2000, many of the world's poorest countries registered strong economic growth and marked reduction in poverty, creating a positive environment for progress in education. Recent turmoil in the global economy has changed that... While financial crisis may be over, the legacy remains a potent threat to progress in education 
These emerging problems, with EFA projections deteriorating and both prioritisation and funding for education decreasing, should not necessarily be attributed to the EFA coordination mechanisms. For instance, the recent global financial crisis, which apparently affected the funding for education and the future outlook of EFA, has nothing to do with the EFA coordination mechanisms. Also, recent deprioritising of EFA may derive from historical educational successes in the early 2000s, which is in fact the "fault" of EFA's success. As observed in this section, however, the context surrounding EFA has changed in the last ten years. Because the EFA coordination mechanisms are expected to increase the visibility of EFA in the international agenda, to mobilise technical and financial resources and to monitor EFA progress, the fact that visibility, resources, and progress are not at acceptable level may have prompted adjustments to to deal with these issues. (Note 19)

\section{The Way Forward}

This paper has examined possible reasons behind the current call for enhancing the EFA coordination mechanisms. In the 1990s, the International Consultative Forum on EFA served as a platform for the global EFA coordination, and several meetings were organised by the Forum to maintain the momentum of EFA and review its progress following the initial Jomtien Conference. Between 2000 and 2001, after the Dakar Forum, the existing EFA coordination mechanisms (notably the WG and the HLG, based on the GMR) were established in order to increase the visibility of EFA within the international political agenda, to mobilise technical and financial resources, and to monitor the EFA progress more systematically. Since the establishment of the WG-HLG mechanisms, the basic format and function of the EFA coordination mechanisms have remained unchanged. In the late 2000s, however, commitment to EFA weakened, education funding decreased and prospects of meeting EFA goals worsened. As the global coordinator of EFA coordination mechanisms, UNESCO is in a position to respond to these emerging challenges by redesigning the EFA coordination mechanisms.

Select efforts have been made to reinstate education as a top priority on the international agenda. One notable development is the merging of the WG with the HLG into the Global EFA Meeting (GEM) to undertake progress review, technical debates and political discussion. Another development is the creation of the High-Level Forum (HLF) comprised of a small number of world leaders in education and other sectors, which is intended to draw the attention of potential educational stakeholders, especially regarding further resource mobilisation. The HLF is organised around major political events such as UN General Assembly meetings to take advantage of the presence of high-level political leaders.

Despite the EFA coordination reform, the new mechanisms are not very different from the existing one. By and large, GEM will assume some of the technical roles of the former WG along with the political roles associated with the former HLG (e.g. the ministerial segment). HLF, on the other hand, will focus on the advocacy aspects of the HLG. Nonetheless, given that the respective roles of the WG and the HLG have become ambiguous in the recent years and the later HLGs did not succeed in maintaining the political visibility of EFA, the reconsideration of the existing EFA coordination at this point may be timely. In order for this new EFA structure function properly, a number of issues remain to be addressed.

\subsection{Uneven Involvement of EFA Stakeholders}

One of the major issues in the EFA coordination has been how to involve developing countries, civil society and the private sector in the decision-making process. While UNESCO addresses this issue by including them in the EFA Steering Committee (the former International Advisory Panel established in 2007), the selection procedure is by no means easy. At the same time, engaging donors in EFA has proven difficult, however important. Many developed countries seem to perceive EFA as a development issue unique to the needs of developing countries.

The involvement of EFA convening agencies also varies. While the value for equity and quality of education is shared among EFA stakeholders, they often promote their own education strategies (e.g. the World Bank's Learning for All) rather than improving widespread performance through partnerships. This trend seems to have intensified in recent years. The new EFA coordination mechanisms are expected to further promote information sharing and policy dialogue among agencies to avoid competition and overlap.

\subsection{Financing Education}

Funding education also continues to pose a major challenge. In the context of EFA, Global Partnership for Education (the former EFA Fast-Track Initiative created in 2002) has developed an innovative financing model with which to provide low-income countries financial and technical support, but has struggled to mobilise the resources necessitated by the model due to political, structural and other constraints (Brown 2012). 
UNESCO has also established the Advisory Panel of Experts on Debt Swaps, and has positioned debt swaps and debt conversion development bonds as an alternative solution to the persistent problem of funding education. Yet, the potential for debt swaps to financing education remains uncertain, in part owing to lack of precedent concerning how much the debt conversion development bonds for education may attract investors (UNESCO2011c). As an impact of the recent financial crisis in education funding, the EFA coordination mechanisms now rely more fully on external factors to ensure resource mobilisation. Yet, it is the EFA coordination's mandate to use available resources effectively and in a manner which avoids the overlapping of education programmes and activities among EFA stakeholders.

\subsection{Dependency on GMR}

Another concern is that the EFA meetings have depended too heavily on the GMR for substance. Indeed, the EFA meetings have been organized according to the publishing date of the GMR. In 2011, for instance, the WG and the HLG took place on 2-3 February and 22-24 March respectively, sandwiching the launching date of 2011 GMR: 1 March. In 2010, the 2010 GMR was launched on 19 January 2010, between the WG 9-11 December 2009 and the HLG 23-25 February 2010. Produced by an independent team, the GMR is meant for better monitoring progress of EFA, and not for the directing the EFA policies. As UNESCO (2011a) recognises, it would have been more reasonable that issues discussed during the WG were integrated into the GMR and taken to the HLG for high-level policy dialogue at the ministerial level, but the WG has been unable to provide substance, which has also led to EFA reform.

Aware of this problem, UNESCO created the Education Research and Foresight team (ERF) in 2010 to deal with and to provide substance to the issue. The ERF has been working on rethinking education in part through the review of previous literature (e.g. the 1972 Learning to be and 1996 Delors Report) and discussion with experts in the field of educational development; however, it remains too early to appraise their efforts at this point.

\subsection{Towards EFA 2015 and Beyond}

Based on the new EFA coordination mechanisms, UNESCO is preparing for strategic planning with the other convening agencies (i.e. the World Bank, UNICEF, UNFPA and UNDP) for 2015. Currently, regional preparatory meetings on EFA and a global conference on EFA are planned to take place in 2014 and 2015, respectively. A new Task Force on EFA 2015 and beyond is also being set up in UNESCO to provide support to the preparation of 2014 regional meetings, the EFA 2015 Assessment and the global conference in 2015 as well as the preparation of post 2015 MDG process and the Global Initiative of the UN Secretary-General on Education.

Beyond 2015, the new EFA coordination mechanisms are expected to continue assisting collective efforts towards the attainment of EFA. Will this new EFA structure function better than the existing one? As with the current EFA structure, the answer will depend on a variety of external as well as internal factors.

\section{References}

Considine, G., \& Zappalà, G. (2002). Factoring influencing the educational performance of students from disadvantaged backgrounds. In T. Eardley, \& B. Bradbury (Eds.), Competing Visions: Referred Processings of the National Social Policy Conference 2001. SPRC Report 1/02, Social Policy Research Centre, University of New South Wales 91-107.

Draxler, A. (2008). New Partnership for EFA: Building on Experiences. Paris: UNESCO-IIEP/World Economic Forum.

Global Campaign for Educatio. (2009). 6 out of 10 for effort but High-Level Group must do better in the future $\begin{array}{lllll}\text { years. } & \text { Retrieved } & \text { May } & \text { 2012, } & \text { from }\end{array}$ http://www.campaignforeducation.org/docs/pressrelease/GCE-Oslo\%20verdict.pdf

Heyneman, S. P. (1999). The Sad Story of UNESCO's Education Statistics. International Journal of Educational Development, 20, 65-74. http:dx.doi.org/10.1016/S0738-0593(98)00068-6

Heyneman, S. P. (2009). The Failure of Education for All as Political Strategy. Prospects: Quarterly Review of Comparative Education, 39(1), 5-10. http:dx.doi.org/10.1007/s11125-009-9107-0

King, K. (2007). Multilateral Agencies in the Construction of the Global Agenda on Education. Comparative Education, 43(3), Special Issue (34), 377-391. http:dx.doi.org/10.1080/03050060701556331

Langhammer, R. (1999). Visualizing Human Capital in Economic Development: Introductory Overview of a Detective Story. In J. L. H. Tan (ed.), Human Capital Formation as an Engine of Growth. Institute of Southeast Asian Studies. 
Little, A., \& Miller, E., (2000). The International Consultative Forum on Education for All 1990: An Evaluation. Paris: UNESCO.

Malone, T. W. (1988). What is coordination theory? Paper presented at the National Science Foundation Coordination Theory Workshop. Massachusetts Institute of Technology.

Malone, T.W., \& Crownstone K. (1994). The interdisciplinary study of coordination. Computing Surveys, 26(1), 87-119.

Marriott, N., \& Goyder, H., (2008). Manual for Monitoring and Evaluating Education Partnerships. Paris: UNESCO-IIEP and World Economic Forum.

Saito, Y. (2001). Sekai Ginkou to Hatten Tojyoukoku e no Kyouiku Kyouryoku [The World Bank's Educational Cooperation to Developing Countries]. In Kaihatsu to Kyouiku [Development and Education] edited by H. Ehara. Tokyo: Shinpyouron.

Skilbeck, M. (2000). Education for All 2000 Assessment: Global Synthesis. Paris: UNESCO.

Steer, L., \& Wathne, C. (2010). Donor Financing of Basic Education: Opportunities and constraints. $\begin{array}{llll}\text { International Journal of Educational Development, } & 30,\end{array}$ http:dx.doi.org/10.1007/j.ijedudev.2010.03.013

UNESCO Institute for Statistics. (2000). Education for All 2000 Assessment: Statistical Document. Paris: UNESCO.

UNESCO. (1990). World Declaration on Education for All. Paris: UNESCO.

UNESCO. (2000). The Dakar Framework for Action. Paris: UNESCO.

UNESCO. (2001). Monitoring Report on Education for All. Paris: UNESCO.

UNESCO. (2005). Resolutions - Records of the General Conference. Paris: UNESCO.

UNESCO. (2007). EFA Global Monitoring Report 2008 - Education for All by 2015 - Will we make it? Paris: UNESCO.

UNESCO. (2010a). The Central Role of Education in the Millennium Development Goals. Paris: UNESCO, UNICEF, The Government of Qatar, Save the Children.

UNESCO. (2010b). EFA Global Monitoring Report 2010 - Reaching the marginalized. Paris: UNESCO and Oxford University Press.

UNESCO. (2010c). Addis Ababa Declaration. Paris: UNESCO.

UNESCO. (2011a). Enhancing Effectiveness of EFA Coordination Mechanisms. Paris: UNESCO.

UNESCO. (2011b). EFA Global Monitoring Report 2011 - The hidden crisis: Armed Conflict and Education. Paris: UNESCO.

UNESCO. (2011c). Debt Swaps and Debt Conversion Development Bonds for Education. Paris: UNESCO.

United Nations. (2012). Millennium Development Goals. Retrieved May 30, 2012, from http://www.un.org/millenniumgoals

World Bank. (2008). World Development Report. Washington DC: World Bank.

\section{Notes}

Note 1. Basic education does not exclusively denote primary education. While there does not seem to be a universal definition of basic education, early childhood education, primary education, lower secondary education, vocational training and adult education can be included in this category. For instance, literacy programmes for adults are considered part of basic education (See King, 2007, p. 379; UNESCO, 2000, p. 66).

Note 2. United Nations Educational, Scientific and Cultural Organisation (UNESCO), the World Bank, the United Nations Children's Fund (UNICEF), United Nations Development Programme (UNDP) and United Nations Population Fund (UNFPA) are the current convening agencies of EFA.

Note 3. According to Marriott and Goyder (2008, p. 19), multi-stakeholder partnerships for education are defined as "pooling and managing of resources" that mobilise "competencies and commitments by public, business and civil society partners, to contribute to the expansion and enhanced quality of education." One of the critical 
reasons why multi-stakeholder partnerships for education are formed is that they are considered to be able to offer better quantity and quality education than a single stakeholder acting alone.

Note 4. The reform of the EFA architecture was also suggested by Steer and Wathne (2010, p. 479): "A stronger global platform could play a normative role and call agencies to account in honouring their commitments. One option would be to strengthen the UNESCO High-level Group by setting up a smaller high-profile commission including senior figures and political leaders."

Note 5. While coordination enables different partners to work together toward common objectives (UNESCO 2011a), partnerships serve as strategies to achieve effective coordination by bringing together a broad range of stakeholders (Draxler 2008). There are various partnerships concerning EFA: Global Partnership for Education, Global Campaign for the UN Girls' Education Initiative and so forth.

Note 6. In 1989, an Inter-Agency Commission, comprising UNICEF, UNDP, UNESCO and the World Bank, was established to organise the Jomtien Conference that took place in 1990. The Inter-Agency Commission was composed of the Executive Secretariat and an International Steering Committee, and this Inter-Agency Commission's structure provided a basic framework for the International Consultative Forum on EFA (Little \& Miller 2000).

Note 7. In the Jomtien conference, the World Declaration on Education for All was adopted with ten articles: 1) meeting basic learning needs; 2) shaping the vision; 3) universalising access and promoting equity; 4) focusing on learning; 5) broadening the means and scope of basic education; 6) enhancing the environment for learning; 7) strengthening partnerships; 8) developing a supportive policy context; 9) mobilising resources; and 10) strengthening international solidarity (UNESCO, 1990, p. 7-12).

Note 8. The Secretariat was engaged in coordination work including the organisation of the Forums. The Steering Committee, on the other hand, provided professional guidance to the Secretariat.

Note 9. The assessment was based on 18 indicators such as gross enrolment in early childhood development programmes, net enrolment ratio at the primary level, pupil-teacher rate, and literacy rate of 15-24 year olds. Over 180 countries participated in the assessment and 167 nations submitted their national reports to UNESCO. See UNESCO Institute for Statistics 2000 for more details.

Note 10. UNESCO Institute for Statistics $(2000$, p. 9) pointed out that population growth was "obviously a major factor in the provision of good quality primary education, with the potential to put a great strain on a country's ability to pay and on educational infrastructure to deliver. In sub-Saharan Africa, for example, there were 24 million more children in 1998 than in 1990. Such large increases in the number of children make the achievement of the Jomtien goals that much harder."

Note 11. The GMR was created in response to the request made for the systematic monitoring progress in EFA. Except for the 2001 GMR, the GMRs have been developed by an independent evaluation team stationed at UNESCO. Each GMR has a theme pertinent to EFA as follows: EFA on Track? (2002), Gender (2003/2004), Quality (2005), Literacy (2006), ECCE (2007), Mid-term Review (2008), Governance (2009), Marginalisation (2010) and Conflict (2011).

Note 12. While the High-Level Group and the Working Group are at the center of UNESCO's EFA coordination, there are several other mechanisms, such as the International Advisory Panel (IAP), the EFA-Fast Track Initiative (FTI), the Collective Consultation of NGOs on EFA (CCNGO) and the E-9 Initiative (UNESCO, 2011a). IAP, comprising about 15 people from multilateral agencies, donors, developing countries, civil society and the private sector, was formed in 2007 and played a crucial in preparation and follow-up of EFA events, particularly HLGs. IAP has now become the EFA Steering Committee. FTI was launched as a global partnership between donors and developing nations to provide financial as well as technical resources to low income countries. FTI became the Global Partnership for Education in 2011. CCNGO is a thematic partnership mechanism created by UNESCO in 1984 to facilitate collective action with civil society. The E-9 Initiative serves as a political platform for nine highly populated countries (Bangladesh, Brazil, China, Egypt, India, Indonesia, Mexico, Nigeria and Pakistan) to discuss their experiences in education, exchange best practices and monitor progress on EFA.

Note 13. Since the First Meeting of the High-Level Group on EFA in Paris in 2001, ten HLGs have taken place: Paris (2001), Abuja (2002), New Delhi (2003), Brasilia (2004), Beijing (2005), Cairo (2006), Dakar (2007), Oslo (2008), Addis Ababa (2010) and Jomtien (2011). The WGs have always taken place in Paris. 
Note 14. These goals are concerned with: 1) poverty and hunger; 2) universal primary education; 3) gender equality; 4) child health; 5) maternal health; 6) HIV/AIDS; 7) environmental sustainability; and 8) global partnership (United Nations, 2012).

Note 15. Ways of addressing the issue of regional coordination were highlighted in the presentation of reports by UNESCO's Regional Bureaux for Education in Beirut, Santiago, Bangkok and Senegal. Showing a great degree of diversity among and within the regions, these presentations also revealed that the world is not on track to reach the EFA goals by 2015, despite encouraging progress in many areas.

Note 16. The General Conference consists of the representatives of all of the 195 UNESCO's Member States. It meets every two years and is attended by Member States and Associate Members, with observers from non-Member-States, intergovernmental organisations, and non-governmental organisations (NGOs).

Note 17. It may be noteworthy that when UNESCO was called on to enhance the effectiveness of its EFA coordination mechanisms during the 9th HLG in February 2010, the 2008 data was not available, which would make the NER progress look even slower.

Note 18. Although the world's GPI is close to 1.00 (0.98 in 2008), progress varies by region.

Note 19. Among these challenges, the most relevant to EFA coordination mechanisms is the decrease is global priority to education. 